\title{
FORMULATION DEVELOPMENT AND EVALUATION OF FAST DISINTEGRATING TABLETS OF CINITAPRIDE HYDROGEN TARTARATE BY USING DIRECT COMPRESSION TECHNIQUE
}

\author{
KRISHNA MOHAN CHINNALA*, SIRISH VODITHALA
}

Department of Pharmaceutics, School of Pharmacy, Nalla Narasimha Reddy Education Society's Group of Institutions, Hyderabad, Telangana, India 500088

Email: drchinnala@gmail.com

Received: 21 Aug 2017, Revised and Accepted: 13 Oct 2017

\section{ABSTRACT}

Objective: In the present study, efforts were taken to develop fast disintegrating tablets of Cinitapride hydrogen tartrate, is a gastro-prokinetic agent and antiulcer agent with an objective to achieve rapid disintegration, and further improving the bioavailability of the drug. Also, to resolve the swallowing problems (Dysphasia) in pediatric, geriatric patients by rapid disintegration in saliva and improve the patient compliance.

Methods: Fast disintegrating tablets were prepared by direct compression method using superdisintegrants like crospovidone (CP), croscarmellose sodium (CCS), sodium starch glycolate (SSG) and combination of super-disintegrants in different concentrations. The prepared formulations were evaluated for the pre-compression parameters like bulk density, tapped density, Carr's compressibility, Hausner's ratio and angle of repose. The prepared batches of fast disintegrating tablets of Cinitapride hydrogen tartarate were evaluated for hardness, weight variation, thickness, friability, drug content, disintegration time, wetting time, water absorption ratio, and in vitro dissolution profile.

Results: Bulk density and tapped density were found in the range of $0.412-0.432 \mathrm{~g} / \mathrm{cc}$ and $0.507-0.528 \mathrm{~g} / \mathrm{cc}$ respectively. In all formulations, tablet weight and thickness were within mean $\pm 9.5 \%$ and mean $\pm 5 \%$ respectively. Wetting time values lie between 19.76 to 39.53 sec. Water absorption ratio ranged from 57.30 to $78.82 \%$. The in vitro disintegration time for all the 12 formulations varied from 17.43 to 38.61 seconds. Formulation F8 which contained crosspovidone have recorded drug release $96.94 \pm 0.47 \%$ at the end of $30 \mathrm{~min}$

Conclusion: The formulation containing crospovidone (F8) showed better performance in terms of disintegration time and drug release when compared to other formulations.

Keywords: Melt in Mouth tablets, Orally disintegrating tablets, Super disintegrants, Gastro-prokinetic, Anti-ulcer

(C) 2017 The Authors. Published by Innovare Academic Sciences Pvt Ltd. This is an open access article under the CC BY license (http://creativecommons.org/licenses/by/4.0/)

DOI: http://dx.doi.org/10.22159/ijcpr.2017v9i6.23659

\section{INTRODUCTION}

\section{Fast disintegrating tablets}

Oral routes of drug administration have wide acceptance up to 50 $60 \%$ of total dosage forms. Solid dosage forms are popular because of low cost, ease of administration, accurate dosage, self medication, pain avoidance and mainly the patient compliance. The most widely used solid dosage forms is the most common problem in patient compliance. Drinking water plays an important role in the swallowing of oral dosage forms. Often times people experience inconvenience in swallowing conventional dosage forms such as tablet. When water is not available, in the case of the motion sickness and sudden episodes are coughing during the common cold, allergic conditions and bronchitis. To improve these drawbacks orally disintegrating tablets or fast dissolving tablets has immersed as alternative solid dosage forms [1].

The united states of food and drug administration defined as the orally disintegrating tablets as "A Solid dosage forms containing medical substance or active ingredient which disintegrates or dissolves rapidly usually within a matter of seconds when place under the tongue [2]. Orally disintegrating tablets can also be called as fast disintegrating tablets. Fast disintegrating tablets are also known as "Fast-dissolving", "Mouth-dissolving", "Rapid dissolve", "Quick-disintegration", "Orally disintegrating", "Rapidmelt", "Fastmelt", "Orodispersible", "Melt-in-mouth", "Quick dissolving", "Porous tablets" "freeze dried wafers", "mouth dissolve" and "Effervescent drug absorption system" [3].

The Center for Drug Evaluation and Research (CDER), US FDA defined Oral Disintegrating Tablets (ODT) as "A solid dosage form containing medicinal substances, which disintegrates rapidly, usually within a matter of seconds, when placed upon the tongue." A fast-dissolving drug delivery system, in most cases, is a tablet that dissolves or disintegrates in the oral cavity without the need of water or chewing. These are also called melt-in-mouth tablets; repi melts, porous tablets, oro-dispersible, quick dissolving or rapid disintegrating tablets.

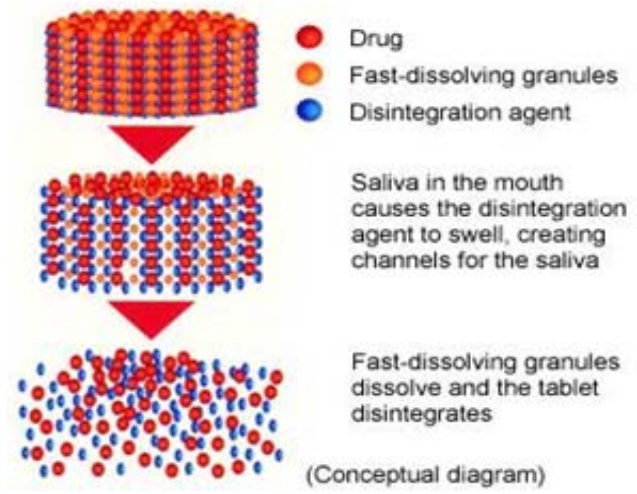

Fig. 1: Mechanism of FDT's

Ideal characteristics of fast disintegrating tablets are

1) Mask or overcome the unacceptable taste of a drug.

2) Have pleasant mouth feel.

3) Convenience of administration and accurate dosing as compared to liquids. 
4) They should easily disintegrate and dissolve

5) Rapid dissolution and absorption of the drug, which may produce rapid onset of action.

6) Exhibit low sensitivity to an environmental condition such as humidity and temperature.

7) Allow the manufacture of tablets using conventional processing and packaging equipment at low cost.

8) They should have low sensitivity to environmental conditions like moisture, temperature etc.

9) They should have high drug loading.

10) Ease of administration to patients who refuse to swallow a tablet, such as pediatric and geriatric patients and psychiatric patients.

\section{Advantages of fast disintegrating tablets}

A fast disintegrating tablet has many advantages of solid dosage forms and liquid dosage forms along with special features which include;

1) Ease of administration is convenient to administer especially for geriatric, pediatric, mentally disabled and bedridden patients who have difficulty in swallowing.

2) Fast onset of therapeutic action as tablet gets disintegrate rapidly along with quick dissolution and absorption in oral cavity

3) Being a solid dosage form it provides luxury of accurate dosing easy portability, manufacturing and good physical and chemical stability and an ideal alternative for pediatric and geriatric patients.
4) Improved patient compliance.

5) Frequently administered when water is not available.

6) Conventional processing and packaging equipment allow the manufacturing of tablets at low cost.

7) Minimum risk of suffocation in airways due to physical obstruction, when ODTs are swallowed, thus they provide improved safety and compliance with their administration.

\section{Limitations of fast disintegrating tablets}

Drugs with relatively large doses are difficult to formulate into FDTs.

For example, antibiotics like ciprofloxacin with adult dose tablet containing about $500 \mathrm{mg}$ at the drug.

1) They are more susceptible to degradation by humidity and temperature.

2) Patients who are taking anticholinergics medication may not be the best candidates for fast disintegrating tablets.

3) Drugs with a short half-life and frequent dosing and those who require controlled or sustained release are unsuitable candidates fast disintegrating tablets.

\section{MATERIALS AND METHODS}

\section{Materials}

Cinitapride Hydrogen tartarate was as gift sample from Symed Laboratories Pvt. Ltd, Hyderabad, Telangana, Crospovidone, Sodium Starch glycolate, Croscarmellose sodium Pregelatinized starch, Mannitol, Magnesium stearate were purchased from Horizon, Hyd, Telangana. Talc was purchased from Asian Scientific, Hyderabad, Telangana.

Table 1: Equipment used in FDT's

\begin{tabular}{ll}
\hline Electronic weighing balance & Schimadzu, Philippines \\
\hline Bulk density apparatus & DBK, India \\
Rotary tablet machine & Karnavati, India \\
Monsanto hardness tester & Inco, India \\
Roche friabilator & DBK, India \\
Screw gauge & Micro, India \\
pH meter & Global, India \\
Disintegration apparatus & DBK, India \\
UV-1800 UV-Spectrophotometer & Systronics, India \\
Dissolution apparatus & Lab India, India \\
FTIR & Bruker, Japan. \\
\hline
\end{tabular}

\section{Methods}

\section{Preparation of a standard graph}

A standard graph of pure drug in the concentration ranges of 2, 4, 6, 8, 10 $\mu \mathrm{g} / \mathrm{ml}$ in the suitable medium was prepared and the graph was plotted by taking the concentrations on $\mathrm{X}$-axis and absorbance on $\mathrm{Y}$-axis.

\section{Preparation method}

\section{Direct compression method}

All the required ingredients were passed through 40 mesh to get uniform size particles and weighed accurately. Drug, mannitol, super disintegrants except lubricant were mixed in the increasing order of their weights in a mortar. To this mixture talc and magnesium stearate were added. The final mixture was shaken manually for 5$10 \mathrm{~min}$ in a plastic bag. This powder was passed through the hopper of 10 station rotary tabletting machine and punched into tablets using $8 \mathrm{~mm} \mathrm{~s} / \mathrm{c}$.

\section{Evaluation of orally disintegration tablet formulations}

Different quality control tests were performed for all the Fast disintegrating tablet formulations to check whether these have met the specifications along with other In vitro tests like wetting time and water absorption ratio.

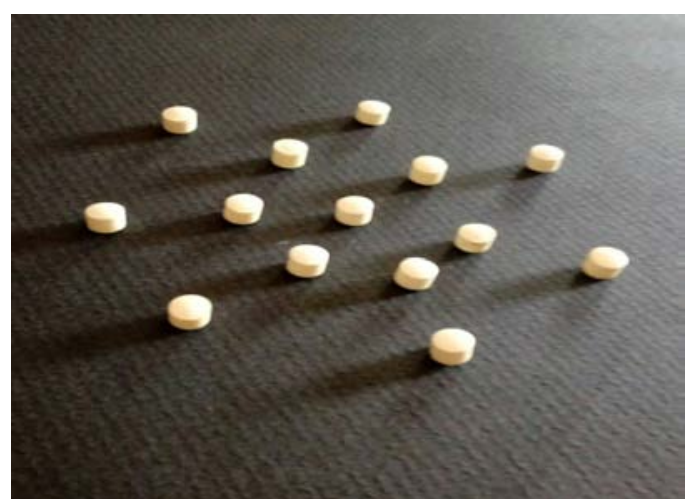

Fig. 2: Cinitapride hydrogen tartarate Fast disintegrating tablets prepared by direct compression technique in the Lab

\section{1) Bulk density (Db) [4]}

It is the ratio of total mass of powder to the bulk volume of powder. It was measured by pouring the weight powder of the drug and excipients and passed through standard sieve \# 20 then it was into a 
measuring cylinder and initial weight was noted. This initial volume is called the bulk volume. It is expressed in $\mathrm{g} / \mathrm{ml}$ and is given by

Bulk density $=$ Mass of the powder/bulk Volume of the powder

\section{2) Tapped density}

Tapped density is determined by placing a graduated cylinder containing a known mass of powder containing the drug and excipients which was transferred into mechanical tapper apparatus, which is operated for a fixed number of taps until the powder bed volume has reached a minimum volume. Using the weight of the granules in the cylinder and this minimum volume, the tapped density may be computed [5].

Tapped density $=$ mass of the powder/Tapped volume of the powder

\section{3) Angle of repose}

The angle of repose was determined using funnel method. The opening end of funnel is closed with thumb until tablet blend is poured. The $5 \mathrm{gm}$ of powder was poured into funnel that can be raised vertically until a maximum cone height (h) was obtained. Radius of the heap (r) was measured and the angle of repose (q) was calculated using the formula [4].

$\operatorname{Tan} \theta=\mathrm{h} / \mathrm{r}$

$\Theta=\operatorname{Tan}^{-1} \mathrm{~h} / \mathrm{r}$

Where $\theta=$ angle of repose.

$r=$ radius of the heap.

\section{4) Carr's index (Or) \% compressibility}

Carr's index (CI) is an important measure that can be obtained from the bulk and tapped densities. In theory less compressible a material the more flowable it is

$\mathrm{CI}=(\mathrm{TD}-\mathrm{BD}) \times 100 / \mathrm{TD}$

TD is the tapped density of the powder

BD is the bulk density of the powder

\section{5) Hausner's Ratio}

Hausner's ratio is an indirect index of ease of powder flow. It is calculated by the following formula

Hausner's ratio $=$ Tapped density/Bulk density

\section{Various in vitro tests performed are}

- Weight variation test

- Thickness measurement

- Hardness and Friability

- Assay

- Wetting time and Water absorption ratio

- Disintegration Time

- Dissolution test

\section{Weight variation test}

\section{Method}

20 tablets were randomly selected from each formulation and their average weight was calculated using digital balance. Individual weight of each tablet was also calculated using the same and compared with the average weight. The mean \pm SD were noted.

\section{Thickness measurement [6]}

\section{Method}

Randomly 10 tablets were taken from each formulation and their thickness was measured using a digital screw gauge. The individual tablet was placed between two anvils of the screw gauge and sliding knob was rotated until the tablet was tightly fitted. The digital reading displayed was noted. The mean \pm SD were noted.

\section{Hardness [7]}

The tablet hardness of different formulations was measured using the Monsanto hardness tester. The tester consists of a barrel containing a compressible spring held between two plungers. The lower plunger was placed in contact with the tablet, and a zero was taken. The upper plunger was then forced against the spring by turning a threaded bolt until the tablet fractures. As the spring is compressed, a pointer rides along a gauge in the barrel to indicate the force. The force of fracture is recorded, and the zero force reading is deducted from it. The hardness for FDTs should be preferably 1-3 kg.

\section{Friability [8]}

This test is performed using a laboratory friability tester known as Roche Friabilator. 10 tablets were weighed and placed in a plastic chambered friabilator attached to a motor, which revolves at a speed of $25 \mathrm{rpm}$, dropping the tablets from a distance of 6 inches with each revolution. The tablets were subjected to 100 revolutions for $4 \mathrm{~min}$. After the process, these tablets were dedusted and reweighed. Percentage loss of tablet weight was calculated.

$$
\% \text { Friability }=\frac{(w 1-w 2)}{w 1} \times 100
$$

Where,

$$
\begin{aligned}
& \text { W1 = Initial weight of the } 20 \text { tablets before testing. } \\
& \text { W2 = Final weight of the } 20 \text { tablets after testing. }
\end{aligned}
$$

Friability values below $1 \%$ are generally acceptable.

\section{Assay}

20 tablets were randomly selected, weighed and finely powdered and quantity of powder equivalent to one tablet was added to 100 ml solvent mixture of $\mathrm{pH} 6.8$ phosphate buffer and methanol (1:1) in a conical flask. An aliquot of solution was centrifuged and supernatant was filtered through a $0.22 \mu$ filter. Absorbance of the resulted supernatant solution was measured using U. V Visible spectrophotometer at a wavelength of $260 \mathrm{~nm}$ against $\mathrm{pH} 6.8$ phosphate buffer as blank.

\section{Wetting time and water absorption ratio (R) [8]}

\section{Method}

Five circular tissue papers were placed in a petri dish with a $10 \mathrm{~cm}$ diameter. Ten milliliters of water containing eosin, a water-soluble dye, was added to the petri dish. The dye solution is used to identify the complete wetting of the tablet surface. A tablet was carefully placed on the surface of tissue paper in the petri dish at room temperature. The time required for water to reach the upper surface of the tablets and completely wet them was noted as the wetting time. The wetting time was recorded using a stopwatch.

The weight of the tablet before keeping in the petri dish was noted $\left(\mathrm{W}_{\mathrm{b}}\right)$ using digital balance. The wetted tablet from the petri dish was taken and reweighed $\left(\mathrm{W}_{\mathrm{a}}\right)$ using the same. The Water absorption ratio, $\mathrm{R}$, was determined according to the following equation:

$\mathrm{R}=100\left(\mathrm{Wa}-\mathrm{W}_{\mathrm{b}}\right) / \mathrm{W}_{\mathrm{b}}$

Where $\mathrm{W}_{\mathrm{b}}$ and $\mathrm{W}_{\mathrm{a}}$ are the weight before and after water absorption respectively.

\section{Disintegration time [9]}

\section{Method}

Disintegration time was also measured using a modified disintegration method $(n=6)$. The disintegration apparatus was the USP dissolution test Apparatus 2, which uses a paddle stirring element and $1000-\mathrm{ml}$ cylindrical vessel at $37^{\circ} \mathrm{C}$. Distilled water was chosen for the disintegration medium instead of a buffer solution. A tablet to be tested was put on the bottom of a sinker, which was placed in the middle of the vessel and hung by a hook to the lid of the 
vessel with a distance of 6-8.5 $\mathrm{cm}$. Disintegration time was determined at the point at which the tablet disintegrated and passed through a screen of the sinker completely. The opening of mesh of the sinker was 3-3.5 $\mathrm{mm}$ in height and 3.5-4 $\mathrm{mm}$ in width.

\section{Dissolution test [10]}

\section{Method}

Dissolution test was carried out using USP rotating paddle method (apparatus 2). The stirring rate was adjusted to $50 \mathrm{rpm} .6 .8 \mathrm{pH}$ phosphate buffer was used as dissolution medium $(900 \mathrm{ml})$ and was maintained at $37 \pm 0.5{ }^{\circ} \mathrm{C}$. Samples of $5 \mathrm{ml}$ were withdrawn at predetermined intervals $(5,10,15,20,25$ and $30 \mathrm{~min})$, filtered using Whatmann filter paper and replaced with $5 \mathrm{ml}$ of fresh dissolution medium. The collected samples were suitably diluted with dissolution medium, where ever necessary and were analyzed for the Cinitapride hydrogen tartrate at $260 \mathrm{~nm}$ by using UV spectrophotometer.

\section{RESULTS AND DISCUSSION}

The present analytical method obeyed Beer's law in the concentration range of $2-10 \mu \mathrm{g} / \mathrm{ml}$ and is suitable for the estimation of Cinitapride hydrogen tartrate from different solutions. The correlation coefficient (r) value for the linear regression equation was found to be 0.997 , indicating a positive correlation between the concentration of Cinitapride hydrogen tartrate and its corresponding absorbance values.

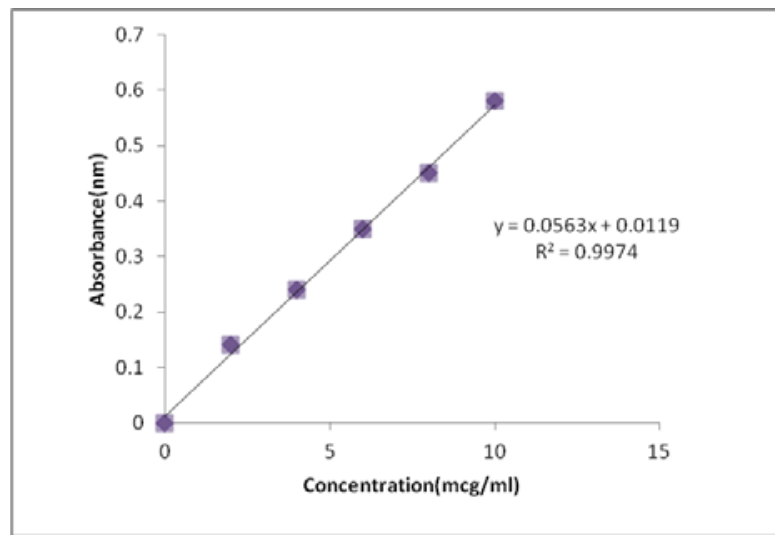

Fig. 3: Calibration curve of cinitapride hydrogen tartrate

Formulation and in vitro evaluation of fast disintegrating tablets by direct compression technique

Table 2: Preformulation characteristics of cinitapride hydrogen tartrate fast disintegrating tablets by direct compression technique

\begin{tabular}{|c|c|c|c|c|c|}
\hline Formulation & Bulk density(g/cc) & Tapped density(g/cc) & Hausner's ratio & Compressibility index (\%) & Angle of repose $(\theta)$ \\
\hline F1 & 0.413 & 0.528 & 1.20 & 16.27 & 31.18 \\
\hline $\mathrm{F} 2$ & 0.420 & 0.521 & 1.20 & 18.56 & 29.24 \\
\hline F3 & 0.431 & 0.511 & 1.22 & 17.80 & 30.12 \\
\hline $\mathrm{F} 4$ & 0.428 & 0.532 & 1.21 & 17.85 & 28.23 \\
\hline F5 & 0.419 & 0.521 & 1.23 & 18.90 & 31.15 \\
\hline F6 & 0.432 & 0.515 & 1.20 & 18.54 & 28.12 \\
\hline F7 & 0.430 & 0.528 & 1.23 & 19.53 & 31.72 \\
\hline F8 & 0.431 & 0.521 & 1.22 & 16.17 & 27.08 \\
\hline F9 & 0.424 & 0.511 & 1.20 & 16.58 & 28.43 \\
\hline F10 & 0.429 & 0.507 & 1.20 & 18.78 & 30.17 \\
\hline F11 & 0.432 & 0.526 & 1.23 & 19.80 & 29.78 \\
\hline F12 & 0.422 & 0.520 & 1.21 & 18.05 & 31.12 \\
\hline
\end{tabular}

Table 3: Tableting characteristics of cinitapride hydrogen tartrate fast disintegrating tablets by direct compression technique

\begin{tabular}{|c|c|c|c|c|c|c|c|c|}
\hline Codes & $\begin{array}{l}\text { Weight } \\
\text { (mg) }\end{array}$ & $\begin{array}{l}\text { Drug } \\
\text { content \%) }\end{array}$ & $\begin{array}{l}\text { Hardness } \\
\left(\mathrm{kg} / \mathrm{cm}^{2}\right)\end{array}$ & $\begin{array}{l}\text { Friability } \\
(\%)\end{array}$ & $\begin{array}{l}\text { Thickness } \\
\text { (mm) }\end{array}$ & $\begin{array}{l}\text { Disintegration } \\
\text { time (sec) }\end{array}$ & $\begin{array}{l}\text { Wetting } \\
\text { time (sec) }\end{array}$ & $\begin{array}{l}\text { Water absorption } \\
\text { ratio (\%) }\end{array}$ \\
\hline F1 & 98.9 & 99.46 & 2.85 & 0.51 & 4.84 & 38.61 & 40.89 & 24.65 \\
\hline F2 & 99.52 & 99.01 & 3.23 & 0.56 & 4.85 & 36.21 & 39.62 & 56.23 \\
\hline F3 & 98.92 & 99.11 & 3.15 & 0.61 & 4.86 & 35.32 & 38.75 & 58.26 \\
\hline F4 & 100.2 & 99.1 & 2.95 & 0.57 & 4.79 & 34.28 & 36.53 & 58.62 \\
\hline F5 & 99.08 & 99.2 & 3.18 & 0.48 & 4.88 & 25.71 & 32.82 & 58.26 \\
\hline F6 & 98.82 & 98.85 & 2.91 & 0.56 & 4.9 & 22.54 & 30.76 & 58.26 \\
\hline F7 & 99.35 & 99.3 & 3.32 & 0.53 & 4.92 & 21.23 & 28.74 & 70.3 \\
\hline F8 & 98.41 & 98.96 & 3.03 & 0.45 & 4.94 & 17.43 & 21.75 & 75.73 \\
\hline F9 & 99.6 & 99.31 & 2.98 & 0.49 & 4.9 & 41.4 & 42.83 & 50.56 \\
\hline F10 & 98.6 & 99.42 & 2.95 & 0.52 & 4.84 & 35.2 & 38.83 & 58.16 \\
\hline F11 & 99.2 & 98.31 & 2.88 & 0.48 & 4.78 & 29.58 & 33.83 & 59.26 \\
\hline F12 & 100.6 & 99.28 & 3.08 & 0.5 & 4.9 & 26.14 & 29.83 & 57.26 \\
\hline
\end{tabular}

Table 4: Cumulative percent cinitapride hydrogen tartrate released from optimized formulation (F8) by direct compression method

\begin{tabular}{ll}
\hline Cumulative \% drug release & F8 \\
\hline Time (min) & 0 \\
\hline 0 & 38.77 \\
5 & 44.59 \\
15 & 54.24 \\
20 & 68.74 \\
25 & 72.42 \\
\hline 0 & 96.94 \\
\hline
\end{tabular}




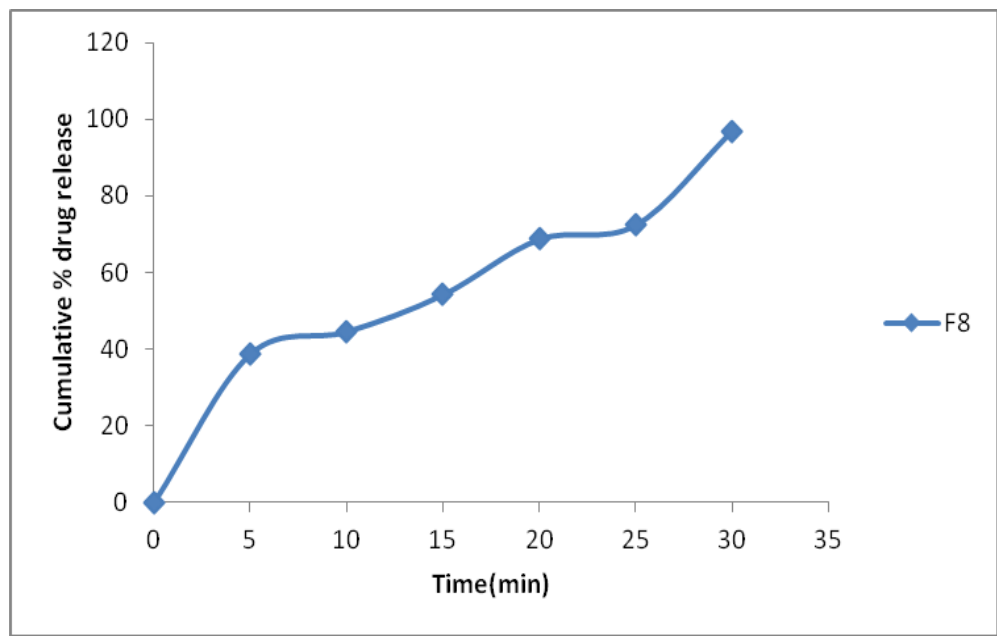

Fig. 4: Graphical representation of cumulative drug release of cinitapride hydrogen tartarate released from optimized formulation (F8) by direct compression technique

\section{FTIR studies}

FTIR spectra of IR spectrum of pure Cinitapride hydrogen tartrate, crosscarmellose sodium, crosspovidone, sodium starch glycolate, and combination thereof were recorded on Perkin Elmer spectrophotometer. The scans were evaluated for presence of principal peaks of drug, shifting and masking of drug peaks due to presence of polymer. The FT-IR spectra of pure Cinitapride hydrogen tartrate, crosscarmellose sodium, crospovidone, sodium starch glycolate, and combination thereof are shown in following fig.

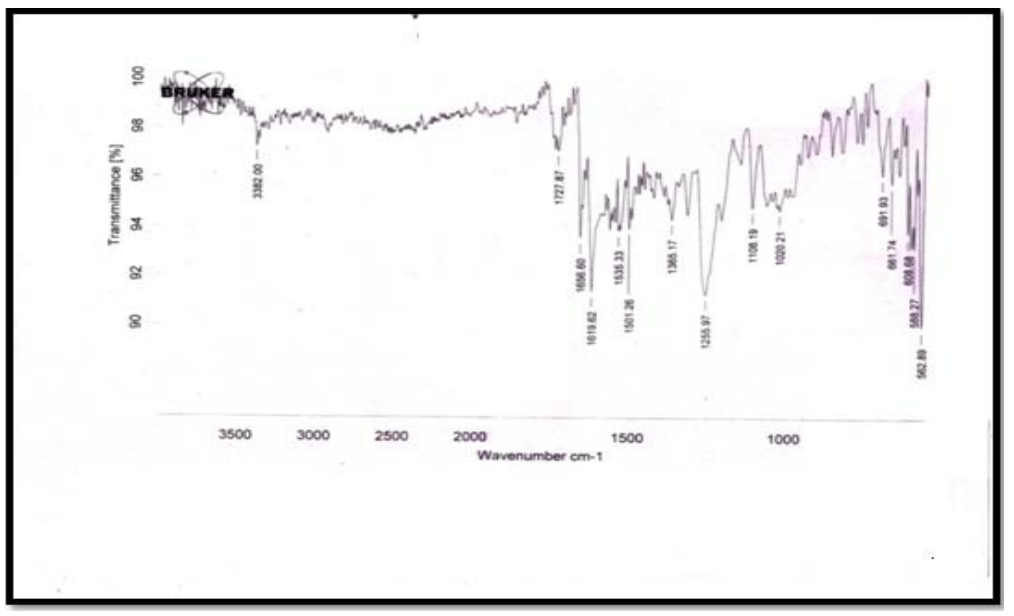

Fig. 5: FTIR spectra of cinitapride hydrogen tartrate

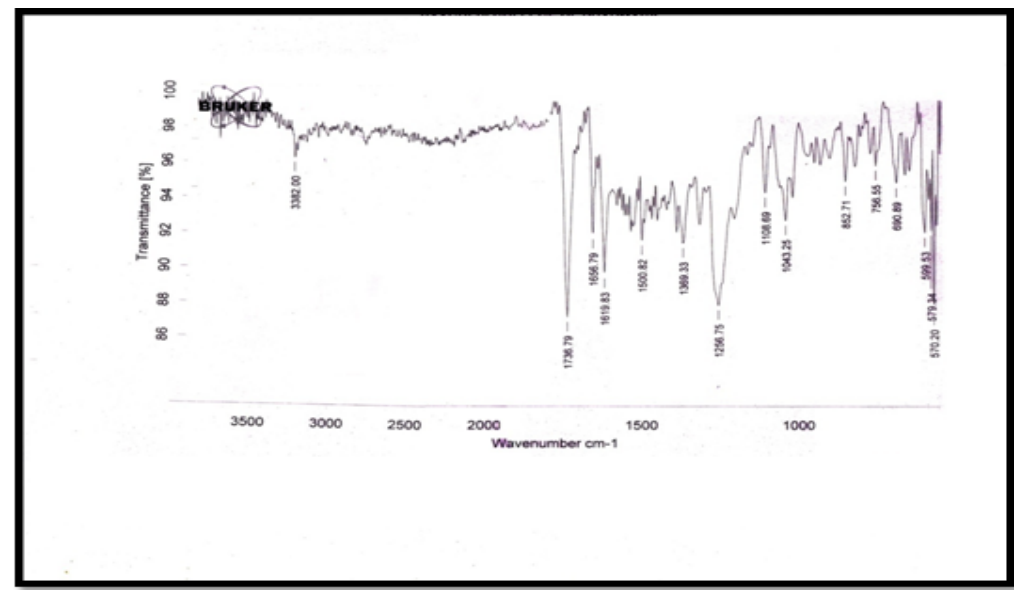

Fig. 6: FTIR spectra of optimized formulation F8 
The above peaks are considered as characteristic peaks of Cinitapride hydrogen tartrate. These peaks were not affected and prominently observed in IR spectra of drug and excipients. This indicates there is no interaction between drug and excipients. The present investigation was to formulate and evaluate Fast disintegrating tablets of Cintapride hydrogen tartrate that disintegrate or disperse in mouth, which overcome the swallowing problems and improves patient compliance. Using various disintegrants like Crospovidone, Crosscarmellose sodium and Sodium starch glycolate tablets were prepared along with other additives. Direct compression method was used for the preparation of tablets. A total number of 12 formulations were prepared and evaluated.

\section{Pre-formulation studies}

Bulk density and tapped density were found in the range of $0.412-$ $0.432 \mathrm{~g} / \mathrm{cc}$ and $0.507-0.528 \mathrm{~g} / \mathrm{cc}$ respectively. The value of Hausner was in between 1.19-1.25 $(<1.25)$ indicating that all batches of powder blends were having good compressibility. Values of angle of repose $(\theta)$ was found in the range of 28.43-32.24 showing that blend of powder was free flowing and can be used for direct compression.

\section{Weight variation and thickness}

In all formulations, tablet weight and thickness were within mean $\pm 9.5 \%$ and mean $\pm 5 \%$ respectively. The average weight in all the twenty four formulations was found to be $98.41 \mathrm{mg}$ to $100.02 \mathrm{mg}$. The thickness varies between 4.79 to $5.15 \mathrm{~mm}$. Friability values were less than $1 \%$ in all cases. Hardness of all the tablets was maintained at 2.85 to $3.32 \mathrm{~kg} / \mathrm{cm} 2$ for all the formulations as mentioned before. Assay was performed and percent drug content of all the tablets were found to be between $98.20 \%$ and $100.14 \%$ of Cintapride hydrogen tartrate, which was within the acceptable limits.

\section{Wetting time}

Wetting time was determined for all the formulations. The values lie between 19.76 to 39.53 sec. The variability in wetting time for different formulations may be due to the changes in the compaction which cannot be controlled during tablet preparation and the type of the disintegrant affected the wetting of the tablets. On comparing the superdisintegrants the formulations containing crospovidone and Crosscarmellose sodium+sodium starch glycolate take less wetting time than the other formulations.

\section{Water absorption ratio}

Water absorption ratio ranged from 57.30 to $78.82 \%$. Crosspovidone and Crosscarmellose sodium perform their disintegrating action by wicking through capillary action and fibrous structure, respectively with minimum gelling. The relative ability of the various disintegrants to wick water into the tablets was studied. After contact with water the tablets containing sodium starch glycolate swelled, the outer edge appeared gel like. Tablets containing crosspovidone quickly wicks water and were hydrated, but were soft as compared with tablets prepared with Crosscarmellose sodium and sodium starch glycolate. The center of the tablets with sodium starch glycolate and Crosscarmellose sodium remained dry and hard.

\section{Disintegration time}

Disintegration time is considered to be important criteria in selecting the best fast disintegrating formulation. The in vitro disintegration time for all the 12 formulations varied from 17.43 to 38.61 seconds. The rapid disintegration was seen in the formulations containing crosspovidone. This is due to rapid uptake of the water from the medium, swelling and burst effect. It is also noticed that as the disintegrant concentration was increased from 5$20 \%$ the time taken for disintegration was reduced. The disintegration time of formulation (F8) containing 20\% CP was found to be lower $(17.43 \mathrm{sec})$ and was selected as the best fast disintegrating formulation among all the 12 formulations.

\section{In vitro dissolution}

The development of dissolution method for fast disintegrating tablets is almost similar to the approach taken for conventional tablets.
The taste masking aspect greatly influences dissolution method development, specifications, and testing. Since Cintapride hydrogen tartrate is slightly bitter in taste, the bitter taste of drug was masked by using sweeteners. It has been reported that USP type II apparatus with a paddle speed of $50 \mathrm{rpm}$ is commonly used for ODT formulations. Slower paddle speeds are utilized to obtain good profiles as these formulations disintegrate rapidly.

In vitro dissolution studies of the prepared fast disintegrating tablets was performed in $\mathrm{pH} 6.8$ phosphate buffer using USP dissolution apparatus type 2 . The dissolution rate was found to increase linearly with increasing concentration of superdisintegrant. Formulation F8 which contained crosspovidone have recorded drug release $96.94 \pm 0.47 \%$ at the end of $30 \mathrm{~min}$.

\section{Drug content}

Assay was performed and percent drug content of all the batches were found to be within the acceptable limits.

\section{FTIR}

The peaks were not affected and prominently observed in FTIR spectra of drug and excipients. This indicates there is no interaction between drug and excipients.

\section{CONCLUSION}

Cinitapride hydrogen tartarate fast disintegrating tablets were prepared by direct compression method using crospovidone, crosscarmellose sodium, sodium starch glycolate exhibited good preformulation and tableting properties. The above used superdisintegrants, formulation containing crospovidone (F8) showed better performance in terms of disintegration time and drug release when compared to other formulations. Fast disintegrating tablets of Cinitapride hydrogen tartarate was found to improve the versatility, convenience, patient compliance leading to an enhanced approach for the administration of drug to the pediatrics and geriatrics. Further studies are required to scale up the future prospects.

\section{ACKNOWLEDGEMENT}

The author is thankful to the management of Nalla Narasimha Reddy Education Society's Group of Institutions for providing necessary facilities at the campus for successful completion of the present work.

\section{CONFLICT OF INTERESTS}

\section{Declared none}

\section{REFERENCES}

1. Hirani JJ. Orally disintegrating tablets: a review. Trop J Pharm Res 2009;8:161-72.

2. Mahmoud AA, Salah S. Fast relief from migraine attacks using fast-disintegrating sublingual zolmitriptan tablets. Drug Dev Ind Pharm 2012;38:762-9.

3. Jeong SH. Material properties for making fast dissolving tablets by a compression method. J Mater Chem 2008;18:3527-35.

4. Kumar A. A review on evaluation and formulation of fast dissolving tablets. Int J Drug Res Technol 2011;1:8-16.

5. Khan T. An approach for rapid disintegrating tablet: a review. Int J Pharm Res Dev 2011;3:170-83.

6. Abdelbary G. The preparation of orally disintegrating tablets using a hydrophilic waxy binder. Int J Pharm 2004;278:423-33.

7. Goel H. Orally disintegrating systems: innovations in formulation and technology. Recent Patents Drug Delivery Formulation 2008;2:258-74.

8. Wanare Ravi. Formulation and evaluation of fast dissolving tablets of azithromycin dihydrate using different super disintegrants. Int J Comprehensive Pharm 2012;3:1-4.

9. Amin. Emerging trends in orally disintegrating tablets; 2005 www.pharminfo.net. [Last accessed on 10 Jul 2017]

10. Nagar Priyanka. Orally disintegrating tablets: formulation, preparation techniques and evaluation. J Appl Pharm Sci 2011;1:35-45 